\title{
PENGUATAN REPUTASI MASAKAN PADANG: SIMBOL PROMOSI PARIWISATA GASTRONOMI DALAM \\ FILM TABULA RASA
}

\author{
Rimalinda Lukitasari \\ Politeknik Internasional Bali \\ Email: rimatanzil@gmail.com
}

\begin{abstract}
Tourism promotion through film is different from advertising due to its disguised promotion process. The application of film-induced tourism practice for tourism promotion has been widely known in the international world, but still less known in Indonesia. Utilizing film to promote tourism is not merely attaching the tourism potential into film, but is also expected to be able to help to form a positive image through the coherence of narrative and cinematic aspect of the respective film. This analysis aimed to enrich the references in the utilizing of film as one of the Indonesian tourism promotional media by identifying and interpreting the meaning of signs in the film Tabula Rasa in relation with the brand reputation strengthening of Padang culinary as part of Indonesian gastronomic tourism promotion. The analysis was done interpretive-qualitatively by using the semiotic theory as a base to interpret the signs and tourism promotion theory as the perspective of the interpretation. The result shows that the film Tabula Rasa is strengthening the brand reputation of Padang culinary by displaying brand identity, brand integrity, and image strengthening through the appearance of emotional appeals which are well packed in narrative and cinematic aspects, so that the film-induced tourism concept as a disguisedly persuasive promotional media is also fulfilled.
\end{abstract}

Keywords: Tourism Promotion, Film-induced Tourism, Gastronomy Tourism, Tabula Rasa

\section{Pendahuluan}

Film adalah bagian dari industri kreatif yang sudah digunakan oleh banyak negara untuk mempromosikan destinasinya. Praktik yang dikenal dengan istilah film tourism atau film-induced tourism ini berbeda dengan iklan. Promosi melalui film cenderung lebih terselubung, dimana informasi dan bujukan dikemas dalam suatu cerita yang memberikan latar konteks sosial terhadap nilai suatu destinasi. 
Hudson dan Ritchie (2006) mengatakan bahwa pelekatan destinasi pada suatu film dapat berdampak terhadap peningkatan brand awareness, peningkatan citra destinasi, dan peningkatan jumlah kunjungan yang signifikan jika dibandingkan dengan praktek pemasaran yang lebih konvensional. Selain peningkatan citra, film juga mampu menciptakan mitos terhadap suatu tempat (Huang, 2013). Beeton (2005) juga menjelaskan bahwa film bekerja lebih baik dari iklan pada umumnya justru karena proses penetrasinya yang halus, sehingga tampak hampir seperti Word-ofMouth (WoM). Beberapa contoh yang cukup fenomenal di dunia film-induced tourism ini adalah pemanfaatan film Lord of The Ring oleh New Zealand, dan Harry Potter oleh Inggris.

Bagi Indonesia, manfaat film-induced tourism sudah pernah dirasakan. Kita dapat melihat bagaimana fenomena film Eat Pray Love dan Laskar Pelangi yang mampu memberikan dampak luar biasa pada bagi promosi destinasi pariwisata di Indonesia. Pada kasus kedua film tersebut, faktor film specific memiliki peran besar dalam mendongkrak angka kunjungan wisata (Imanjaya dan Kusumawardhana, 2016). Lukitasari (2017) menunjukkan dalam penelitiannya bahwa peran narasi pada film sangat berpengaruh dalam menciptakan daya tarik emosional, selain pengaplikasian elemen sinematik yang baik. Daya tarik emosional ini berperan besar dalam mempengaruhi preferensi audiens untuk memilih destinasi yang ditampilkan.

Promosi untuk suatu destinasi, tidak lagi terbatas pada pelekatan destinasi tersebut sebagai lokasi atau latar cerita, namun juga dapat menggunakan salah satu elemen atraksi tertentu pada destinasi yang mampu menunjukkan potensi wisata, salah satunya melalui kekayaan gastronomi. Menurut uraian Richards (2002: 3-19), gastronomi dapat menjadi penanda identitas budaya suatu masyarakat maupun pembawa jejak sejarah perkembangan budaya masyarakat tersebut. Dengan mempromosikan potensi daya tarik gastronomi Indonesia, tentunya juga menjadi 
promosi terhadap identitas dan kekayaan budaya yang menjadi salah satu kekuatan pariwisata Indonesia.

Berbicara tentang promosi pariwisata gastronomi melalui film, terdapat sebuah film Indonesia bertema kuliner Padang yang dimanfaatkan oleh Kementerian Pariwisata Republik Indonesia dengan judul Tabula Rasa. Film ini telah berhasil ditayangkan di berbagai festival film internasional bergensi, di antaranya festival film Cannes (2015) dan Sofia International Film Festival (SIFF) - Bulgaria (2018). Pada penayangan di Bulgaria Dubes R.I untuk Sofia, Sri Astari Rasjid, menyatakan harapan dengan adanya promosi terpadu kuliner, film dan pariwisata Indonesia, dapat berkontribusi dalam peningkatan jumlah wisatawan Indonesia. Dijelaskan bahwa pada kegiatan tersebut, penonton menunjukkan antusiasme terhadap film Tabula Rasa. Penayangan di kedua festival film tersebut sama-sama dibarengi oleh penyajian ratusan porsi Rendang sebagai salah satu elemen experience yang ingin disajikan oleh pihak rumah produksi maupun pemerintah Indonesia. (CNN, 2015; Antara News, 2015; Kementerian Luar Negeri Republik Indonesia, 2018)

Tabula Rasa (2014) merupakan film Indonesia yang menggunakan makanan padang sebagai penggerak ceritanya. Film ini disebutkan sebagai film Indonesia pertama yang mengetengahkan makanan tradisional Indonesia (Liputan 6, 2014; Metro TV News, 2014; Republika, 2014). Pada dekade yang bersamaan dengan kemunculan film ini, tahun 2011, Rendang mendapatkan publikasi internasional sebagai makanan terenak di dunia versi CNN reader's choice, pertama kali dipublikasikan pada tahun 2011, kemudian kembali dipublikasikan pada tahun 2017 (CNN, 2017). Berita mengenai rendang ini juga dimuat dalam portal Wonderful Indonesia sebagai salah satu artikel promosi pariwisata (Kementerian Pariwisata Republik Indonesia, 2018). Adanya publikasi terhadap makanan Rendang, dan kemudian kehadiran film ini di SIFF, serta adanya harapan agar film ini dapat menjadi salah satu media promosi pariwisata kuliner Indonesia, menjadikan film ini menarik untuk diteliti. Salah satu permasalahan yang dapat dikaji adalah simbol- 
simbol apa sajakah yang muncul dalam konten film ini yang memang dapat menjadi penguat citra untuk mendukung elemen publikasi lainnya terhadap atraksi makanan lokal Indonesia, khususnya masakan Padang?

Untuk menjawab pertanyaan tersebut, kajian ini berfokus kepada simbol-simbol promosi pariwisata gastronomi yang muncul pada konten film Tabula Rasa, dengan cara mengidentifikasi tanda dan mengintepretasikan makna tanda dalam kaitannya dengan pemenuhan tujuan promosi pariwisata, terutama dalam hal penguatan citra dan reputasi masakan Padang. Hasil kajian ini diharapkan dapat memperkaya referensi dalam membangun promosi pariwisata melalui film secara umum, dan dalam mengembangkan bentuk-bentuk promosi sinergis lainnya untuk penguatan citra masakan Padang sebagai bagian dari pariwisata gastronomi Indonesia.

\section{Teori dan Metode}

Kajian ini menggunakan pendekatan kualitatif-intrepretif untuk mengidentifikasi simbol-simbol promosi parwisata dalam film Tabula Rasa, serta menganalisis kontribusinya dalam pemenuhan tujuan promosi pariwisata gastronomi Indonesia. Proses interpretasi dan evaluasi dilakukan dengan mengadopsi kaidah-kaidah pengujian hasil intepretasi yang diajukan oleh Purwasito (2005) yaitu dengan berdasarkan konvensi (common sense), corak ideologi pelaku komunikasi, konteks penggunaan tanda, kaitan dengan tanda-tanda lainnya, fungsi tanda dalam masyarakat, teks-teks, penafsiran dari penafsir lain, penafsiran penafsir berpengalaman, dan berdasarkan pengalaman intelektual peneliti. Penafsiran penafsir lain didapatkan melalui penelusuran internet terhadap artikel blo-blog mandiri yang mengulas mengenai film Tabula Rasa.

Teori yang digunakan dalam penelitian ini meliputi teori semiotika serta teori promosi pariwisata. Teori semiotika digunakan sebagai dasar untuk mengintepretasikan simbol-simbol dalam konten film 'Tabula Rasa', sedangkan, teori promosi pariwisata digunakan sebagai sudut pandang intepretasi yang 
difokuskan. Sobur (2013) menyebutkan bahwa manusia berkomunikasi dan memahami dunia dengan melalui perantaraan tanda-tanda. Film sebagai suatu suatu media dalam mengkomunikasikan ide dari pembuat kepada khalayak penonton, tentu saja juga menghadirkan serangkaian tanda-tanda sebagai alat perantara. Tanda-tanda yang dianggap paling berpengaruh dalam menyampaikan pesan dalam film adalah gambar dan suara, termasuk di dalamnya dialog, noise, dan musik (Sobur, 2013). Semiotika merupakan ilmu yang mempelajari tentang tanda-tanda tersebut. Dalam model semiotika Pierce, tanda merupakan perpaduan dari tiga komponen utama, yaitu representanmen, obyek, dan intepretan. Representanmen adalah konsep yang mewakili suatu obyek. Sedangkan, kesan yang timbul dari representanmen adalah intepretan (Chandler, 2007).

Model semiotika Pierce (Sobur, 2013) menjelaskan tanda sendiri terdiri dari ikon, indeks, dan simbol. Ikon merupakan sebuah benda yang karakteriksiknya dapat mewakili konsep yang direpresentasikannya. Indeks adalah suatu hal yang dapat digunakan untuk mengindikasikan hal lainnya karena terdapat asosiasi menetap di antara keduanya, contohnya api dan asap, Sedangkan simbol adalah "tanda yang mengacu kepada obyek tertentu di luar tanda itu sendiri." (Sobur, 2013). Simbol merupakan bagian dari suatu konteks sosial tertentu yang memerlukan suatu proses pemaknaan lebih lanjut untuk dapat menghubungkan tanda yang dimaksud dengan obyek lain yang diwakilinya.

Semiotika, sebagai suatu metode kualitatif-interpretatif, mengandalkan suatu konvensi dalam proses interpretasinya (Piliang, 2010). Jackobson menjelaskan konvensi ini sebagai suatu kode, dimana dalam proses intepretasinya dibutuhkan pengetahuan mengenai keadaan sosial, genre pesan, dan hubungan antara keduanya (Chandler, 2007). Dalam semiologi Barthes, makna yang memperlihatkan hubungan yang eksplisit dalam proses pemaknaannya merupakan makna tingkat pertama atau denotatif. Sedangkan, makna yang membutuhkan intepretasi yang melibatkan kode-kode tersebut disebutkan sebagai makna tingkat kedua atau makna 
konotatif. Makna konotatif itu sendiri berkaitan dengan ideologi dan mitologi. (Piliang, 2012; Thwaites, dkk., 2011). Resepsi merupakan pandangan dalam semiotika yang memusatkan kajian dari sudut pandang audiens sebagai pihak yang melakukan decoding terhadap suatu tanda atau pesan. Makna tanda dapat diartikan sesuai dengan yang diinginkan penyampai pesan, namun juga dapat dimaknai sebagai hal yang berbeda (Hall, 1999).

Promosi merupakan suatu bagian dari Komunikasi Pemasaran Terpadu (Integrated Marketing Communication), yang menggabungkan fungsi-fungsi komunikasi dan pemasaran dalam satu badan. Tujuan dasar dari kegiatan promosi adalah untuk menyebarkan informasi, mempengaruhi perilaku konsumerisme audiens dan mengingatkan audiens mengenai produk, organisasi, maupun bauran pemasaran itu sendiri (Perreault dan McCarthy, 2002). Yoeti (2013) membagi komunikasi pemasaran ke dalam dua bagian, yaitu komunikasi informatif dan komunikasi persuasif. Kotler, et.al (2010) juga menjelaskan bahwa dalam pemasaran, reputasi merk (brand reputation) memegang peranan penting dalam pertimbangan calon konsumen untuk memilih suatu produk. Tentu saja ini juga berlaku dalam industri parwisata dimana fitur-fitur yang mirip dapat dimiliki oleh banyak destinasi sehingga tiga konsep yang ditawarkan Kotler menjadi hal yang harus terus diperhitungkan dalam perencanaan kegiatan pemasaran, termasuk dalam kegiatan promosi. Ketiga konsep itu adalah identitas, integritas, dan citra. Maksudnya adalah bahwa pesan promosi harus dapat secara jelas menunjukkan identitas unik suatu produk, menguatkannya dengan integritas yang otentik, untuk membangun citra merk yang kuat. Suatu citra merk yang kuat memungkinkan calon konsumen untuk menjatuhkan preferensi berdasarkan alasan emosional daripada alasan fungsionalnya. Daya tarik emosional dalam kegiatan promosi muncul berupa sentimen sosial-psikologis dalam mempengaruhi preferensi audiens. (Kotler dan Armstrong, 2012; Morissan, 2010). 


\section{Film Tabula Rasa}

Film Tabula Rasa merupakan film Indonesia yang diproduksi oleh Lifelike Pictures dan dirilis tahun 2014. Sheila Timothy adalah produser film ini, sedangkan sutradara yang menggarap film adalah Adriyanto Dewo dengan bekerjasama dengan Tumpal Tampubolon sebagai penulis skenario. Penata musik dipercayakan kepada Indra Perkasa dan aspek sineamatogafi ditangani oleh Amalia T.S. Film ini juga menggunakan penasehat kuliner dalam persiapan produksinya yaitu Chef Adzan Tri Budiman dan seorang entrepeneur masakan minang Reno Andam Suri (Tabula Rasa, 2014)

Film yang menggunakan tagline "Makanan adalah Itikad Baik untuk Bertemu" ini dijelaskan oleh Sheila Timothy, selaku produser, sebagai suatu harapan untuk "merayakan kebersamaan" (Antara News, 2018). Film ini menceritakan pertemuan dan konflik antara seorang pemuda Papua bernama Hans (Jimmy Kobogao) dengan tiga orang Padang yang menjalankan usaha Warung Padang 'Takana Juo', yaitu Mak (Dewi Irawan), Parmanto (Yayu Unru), dan Natsir (Ozzol Ramdan) (IMDB, 2014; Tabula Rasa, 2014). Bahasa yang digunakan dalam film mayoritas merupakan percampuran antara Bahasa Minang, Bahasa Indonesia, dan Bahasa Indonesia dialek Papua. Format DVD film ini juga dilengkapi dengan pilihan teks terjemahan dalam Bahasa Indonesia dan Bahasa Inggris.

Kisah dalam film ini menceritakan konflik sederhana seputar kesulitan hidup dan perjuangan masyarakat menengah ke bawah dalam persaingan usaha dengan menggunakan makanan sebagai benang merah. Persimpangan antara prinsip untuk tetap mempertahankan kualitas masakan dan keinginan untuk beralih pada bahanbahan yang lebih murah sebagai usaha untuk menaikkan jumlah keuntungan. Berbalut pada konflik-konflik tersebut, film ini berusaha menunjukkan kearifan lokal Indonesia dalam memasak masakan tradisional, dalam hal ini masakan Padang. 


\section{Pesona Masakan Padang pada Film Tabula Rasa}

Setelah melakukan penelitian mendalam terhadap film “Tabula Rasa' ini, ditemukan bahwa penguatan citra juga memberikan efek persuasi kepada penonton untuk menyantap masakan Padang. Penguatan citra masakan Padang sebagai bagian dari salah satu kekayaan budaya yang menjadi kekuatan pariwisata Indonesia hadir dari beberapa aspek, yaitu pesona kelezatan masakan, pesona otentisitas dan identitas, serta pesona nuansa kekeluargaan dan kerinduan akan kampung halaman. Di bawah ini, akan dibahas secara lebih mendalam mengenai unsur-unsur dalam film Tabula Rasa yang memuat efek promotif bagi pariwisata gastronomi di Indonesia, khususnya masakan padang.

\section{Pesona Kelezatan Makanan}

Para penonton yang telah menonton film 'Tabula Rasa' tampaknya sepakat bahwa tampilan gambar pada film ini mampu membangkitkan selera makan. Seperti merebaknya budaya foodporn di media sosial yang menampilkan gambargambar makanan secara close up, film ini juga memunculkan rasa yang menggugah selera melalui pengambilan gambar jarak dekat (close up). Namun, hal itu bukan satu-satunya hal yang dapat memudahkan penonton untuk tertransportasi ke dalam cerita. Narasi yang disajikan juga berkontribusi dalam mengajak penonton untuk ikut merasakan aroma dan rasa masakan secara metafora.

Film ini tidak sekedar menampilkan gambar makanan yang akan dihidangkan, namun juga proses pembuatannya. Mulai dari proses menghaluskan bumbu-bumbu dapur khas Indonesia seperti bawang merah dan cabai, proses pemerasan santan secara tradisional, proses pemasakan di atas tungku tradisional dengan kayu bakar, semuanya seolah mengajak penonton untuk membayangkan rasa yang mungkin didapatkannya jika menyantap masakan-masakan tersebut.

Penggambaran ini tidak hanya bekerja sebagai pengingat (reminder) untuk para penonton yang sudah terbiasa dengan rasa masakan Padang, namun dapat 
juga bekerja sebagai pemberi informasi pada para penonton yang masih asing dengan rasa masakan Indonesia ini. Contoh tanda-tanda yang digunakan film ini untuk membangkitkan indera penonton secara metafora dimulai dari saat Mak dan Hans belanja di pasar. Pada adegan tersebut Mak mengkomentari harga bawang merah lokal dan bawang merah impor yang cukup signifikan. Gambaran adegan tersebut adalah sebagai berikut:
Hans
: “Kenapa Mak"
Mak
: "Bawangnya impor semua."
"Dia murah tapi hambar." (Sambil menunjukkan bawang merah impor di tangannya kepada Hans)

Kemudian Mak meletakkan Bawang Merah impor kembali ke tumpukannya dan mengambil bawang merah lokal di sebelahnya.

Mak

: "Kalau ini bawang lokal, rasanya tajam. Cium!”

(Mak menyodorkan bawang merah lokal ditangannya ke hidung Hans)

"Hasil dari tanah kita sendiri."

"Kamu bingung kenapa bawang impor tuh lebih mahal daripada bawang lokal?"

"Mak juga bingung."

"Yasudah kasih ini aja." (Mak berkata kepada penjual Bawang sambal mengurai-urai bawang merah lokal yang jumlahnya tidak terlalu banyak di atas tampah).

Penjual : : "Berapa kilo, Mak?"

Mak : "Dua kilo"

Adegan di atas, terutama saat Mak menyodorkan bawang merah lokal dan berkata bahwa baunya tajam, dapat menjadi pengantar bagi penonton untuk mulai merasakan bahwa bawang merah yang akan digunakan untuk memasak adalah bawang merah lokal Indonesia yang rasanya lebih tajam. Setelah tahapan pengantar ini, penonton diajak untuk mengikuti Mak dan Hans memasak di dapur yang 
memperlihatkan gambar Hans menghaluskan bawang di atas cobek batu hingga meneteskan air mata. Scene ini dapat membantu membawa penonton untuk ikut merasakan aroma tajam khas bawang merah dan pedasnya cabai merah yang menggugah selera. Selanjutnya, tampak scene Hans memeras santan kental dan Mak memotong daging sapi segar. Kedua hal ini kembali menambah simbolisasi segarnya bahan yang digunakan dalam masakan. Bahan-bahan yang segar tentunya akan merupakan salah satu resep untuk membuat masakan yang enak.

Berikutnya, diperlihatkan bagaimana santan kental dituangkan ke atas wajan panas dengan menampilkan suara desisan ketika santan menyentuh wajan panas tersebut disertai kepulan asap, diikuti dengan dimasukkannya bumbu-bumbu dan potongan daging sapi. Dengan memerahnya warna santan yang mengental setelah proses pemasakan yang lama dan perlahan, penonton diajak membayangkan gurihnya masakan yang ada di depan layar, seperti halnya yang terjadi ketika penonton dihadapkan pada acara realiti masak-memasak di depan televisi. Sineas dalam film ini berhasil menyoroti aspek-aspek kecil untuk memberikan penekananpenekanan dalam penampilan sehingga membantu penonton untuk tertransportasi ke dapur Mak secara metafora. Seperti yang dikatakan oleh Kukuh Giaji (2014) dalam ulasannya, “Jangan lupakan rempah-rempah yang tengah digilling dan membuat kita nyaris menghirup aroma tersebut".

Tentu saja film ini tidak hanya berhenti sampai di sini. Dalam adegan Mak dan Hans memasak di dapur ini juga diperlihatkan shot Mak yang sedang memasak Dendeng Batokok Lado Mudo dengan pertama-tama menumbuk daging sapi empuk di atas cobek batu dan menghaluskan bumbu dapur dan rempah-rempah. Dengan menunjukkan shot melumuri daging sapi dengan bumbu sebelum disusun di atas alat pemanggang, seolah menyiratkan adanya aroma bawang merah dan bawang putih yang dapat tercium ketika daging geprek tersebut dipanggang di atas api. Pengambilan gambar secara close up terhadap proses pemanggangan daging juga membuat penonton membayangkan aroma bumbu halus yang bertemu aroma 
asap. Setelah itu diperlihatkan gambar daging panggang yang dilumuri sambal hijau di atasnya serta diberi perasan jeruk nipis. Gabungan dari gambar-gambar ini tentunya mempermudah penonton untuk membayangkan rasa masakan yang memadukan aroma rempah, asap, pedas, dan kecut segar jeruk nipis (Gambar 1).
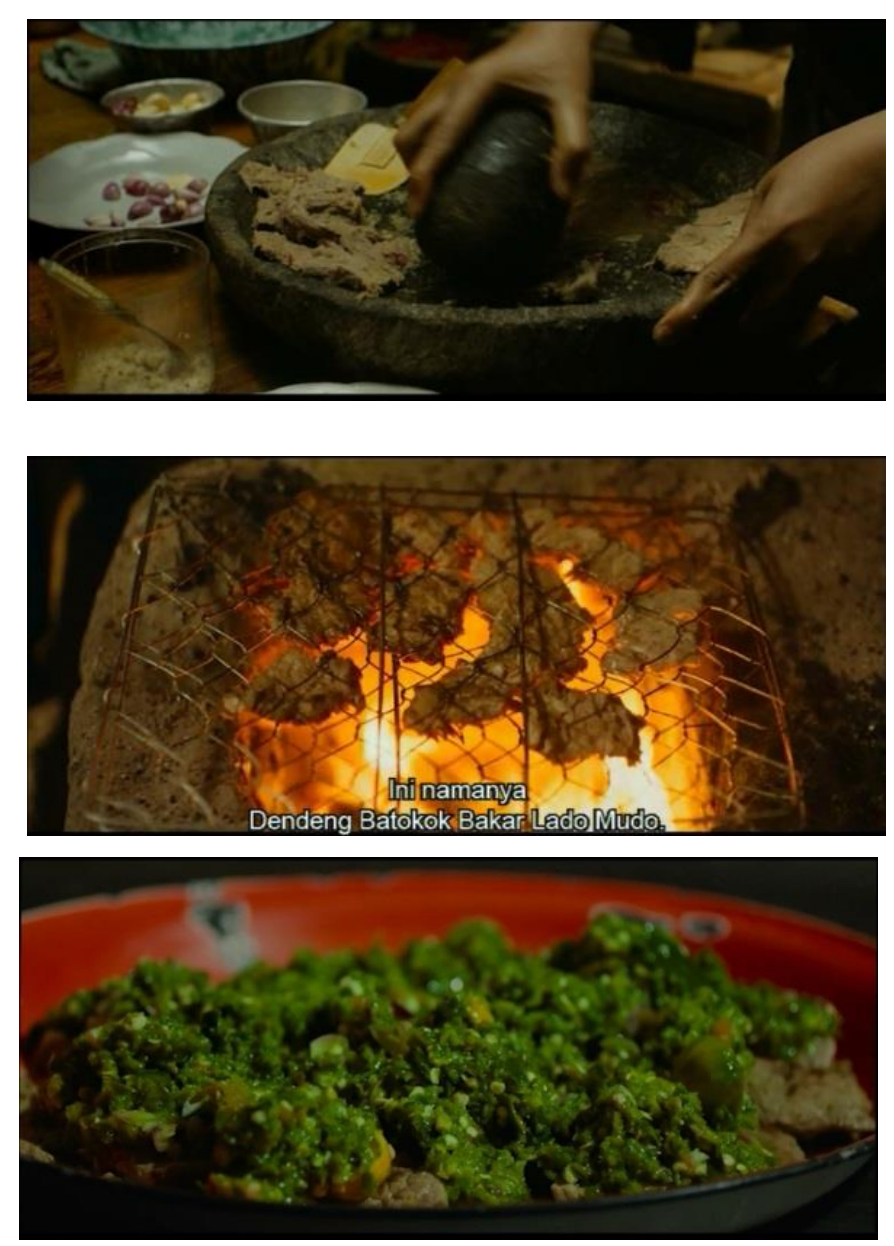

Gambar 1. Proses Memasak Dendeng Batokok Lado Mudo Sumber: Film Tabula Rasa produksi Lifelike Pictures

\section{Pesona Identitas Otentik dan Integritas Masakan Padang}

Film 'Tabula Rasa' menampilkan cerita kehidupan sederhana secara apa adanya. Timothy Stevano dalam blog 'Kritikus Film Gadungan' (2014), menyebutkan film ini sebagai film yang "realistis dan believable". Konflik yang ditampilkan sederhana dan merupakan cermin kehidupan nyata yang dihadapi banyak usaha-usaha berskala kecil dalam persaingan dengan pelaku bisnis berjaringan. Adegan-adegan 
berbelanja ke pasar dan proses memasak di dapur yang tradisional memunculkan identitas dan keunikan yang dapat menjadi daya tarik tersendiri.

Suasana pasar yang ditampilkan dalam film merupakan lokasi pasar sesungguhnya yang tidak dibuat-buat. Terdapat adegan-adegan di lorong-lorong gelap dan sempit tipikal pasar di Indonesia lengkap dengan suasana becek sehabis hujan. Hal ini memberikan gambaran suasana yang otentik ala Indonesia. Tidak seperti pada gambar-gambar makanan yang dibuat hampir seperti iklan masakan Indonesia, suasana asli lingkungan pasar dibuat apa adanya. Hal ini memberi keseimbangan pada film ini dan memberikan konteks sosial yang lebih dapat dipercaya sehingga penonton dapat melihat cerita dalam film sebagai cerminan kenyataan, bukan semata-mata iklan promosi pariwisata.

Menurut survei yang dilakukan oleh Expedia (2016), otentisitas merupakan salah satu faktor yang sangat berperan dalam keputusan pembelian oleh para wisatawan millennial. Melalui adegan-adegan dalam film ini, suasana otentik dapur tradisional milik Mak tidak hanya hadir secara denotatif sebagai dapur saja, tetapi disisipkan alasan-alasan kearifan lokal yang dijunjung oleh Mak yang tetap mempertahankan proses memasak tradisional tersebut. Contohnya pada adegan Hans dan Mak yang sedang memasak dengan dialog seperti di bawah ini:

Hans memeras santan dengan alat peras tradisional

Hans : "Mak, ini lagi saya mau tanya dari dulu sekali"

"Di pasar sana toh, kan sudah ada yang jual santan."

“Kenapa kita masih parut trus peras seperti ini lagi?"

(Sambil menekan tuas alat pemeras santan tradisional)

Mak : "Hans, memasak itu harus dirasakan semuanya dengan tangan."

“Namanya rasa tangan" 
Hans menghidupkan tungku api tradisional dengan cara meniup melalui rongga sebatang bambu (Gambar 4.2.1)
Hans : : Mak, ini tidak bisakah pakai kompor gas sajakah?"
"Ini macam bakar batu di Papua sana saja nih."
"Pakai kayu lagi nih, bikin lama saja, duh."
Mak : : "Masak Rendang tuh, apinya harus kecil dan tahan lama."
"Pakai gas bisa, tapi gasnya kamu yang bayar."

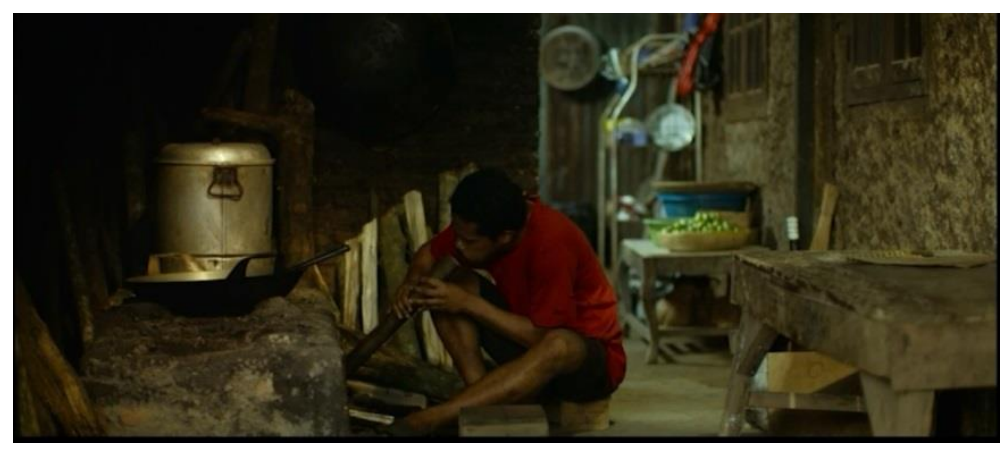

Gambar 2. Hans Menghidupkan Tungku Api Tradisional Sumber: Film Tabula Rasa produksi Lifelike Pictures

Dari cuplikan dialog di atas dapat dilihat bahwa Mak seolah menjelaskan juga kepada penonton bahwa masakan khas Padang, terutama Rendang yang tampak lezat di depan layar tersebut, dihasilkan dari proses memasak yang panjang dan rasanya akan lebih maksimal jika dimasak secara tradisional. Hal ini menyiratkan bahwa dapur tradisional Indonesia tetap dipertahankan bukan karena gaya hidup Indonesia masih primitif, tetapi untuk menjaga otentisitas rasa. Kemunculan konflik persaingan antara warung Takana Juo sebagai warung berskala rumah tangga dengan Rumah Makan Caniago sebagai simbolisasi bisnis berskala besar juga menguatkan pesan tentang pentingnya menjaga integritas dan identitas dalam pengolahan masakan Padang. Dengan menunjukkan adegan warung Takana Juo yang akhirnya lebih ramai daripada Rumah Makan Caniago, menyiratkan bahwa yang terutama dari kelangsungan bisnis makanan adalah rasa yang dihasilkan dari kualitas bahan dan pengolahan. Salah satu contoh integritas dan identitas 
digambarkan dalam adegan Mak yang bersikukuh mempertahankan penggunaan bahan berkualitas, dalam hal ini bawang merah lokal. Sedangkan, Parmanto bersikukuh untuk menggunakan bawang merah impor yang lebih murah agar biaya produksi dapat ditekan. Hadirnya perbandingan antara visualisasi dapur modern rumah makan Caniago dan dapur tradisional warung Takana Juo (Gambar 3) juga dapat menjadi salah satu simbol penguat yang menunjukkan bahwa dapur modern tidak selalu lebih baik dari dapur tradisional dalam membuat makanan lezat berkualitas.
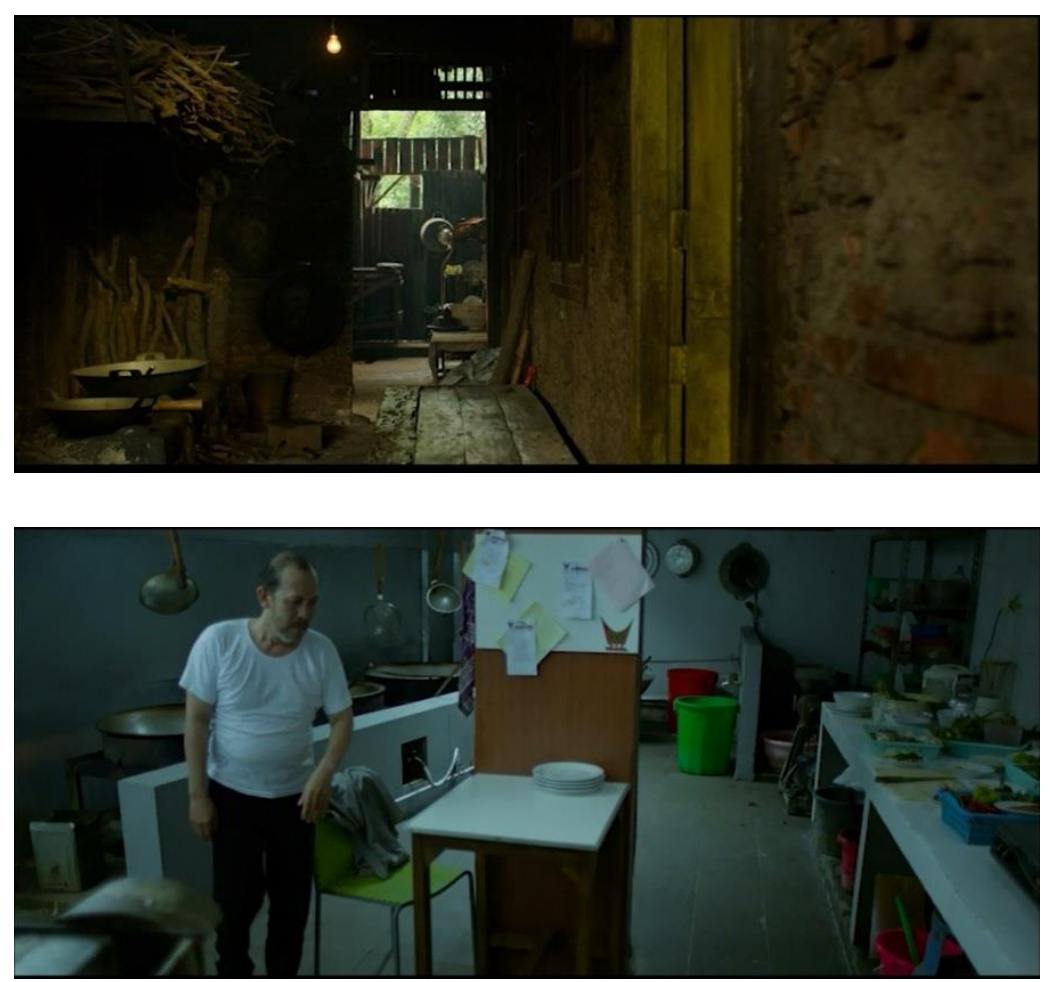

Gambar 3. Visualisasi Dapur Tradisional Takana Juo dan Dapur Modern Caniago

Sumber: Film Tabula Rasa produkksi Lifelike Pictures

Rizky Ramadhan (2014) dalam ulasannya terhadap film Tabula Rasa menyebutkan: "Kita bakal tau kalau masakan padang yang enak dihasilkan dari cabe yang diulek pake batu dengan dua tangan, santen yang diperas tampa mesin, dan rendang yang dimasak empat jam dengan kayu bakar". Hal ini tentu saja dapat juga berdampak pada persuasi bagi penonton di luar negeri untuk mengunjungi Indonesia agar dapat 
merasakan otentisitas rasa Rendang tersebut yang dimasak di dapur tradisional Indonesia dengan cara tradisional Indonesia, sebab dapur semacam itu bukan merupakan dapur yang umum dapat ditemui di negara-negara lain, terutama di negara-negara maju. Identitas lainnya juga tampil dalam beberapa shot yang menunjukkan model penataan piring khas rumah makan padang dengan cara ditumpuk-tumpuk (Gambar 4).
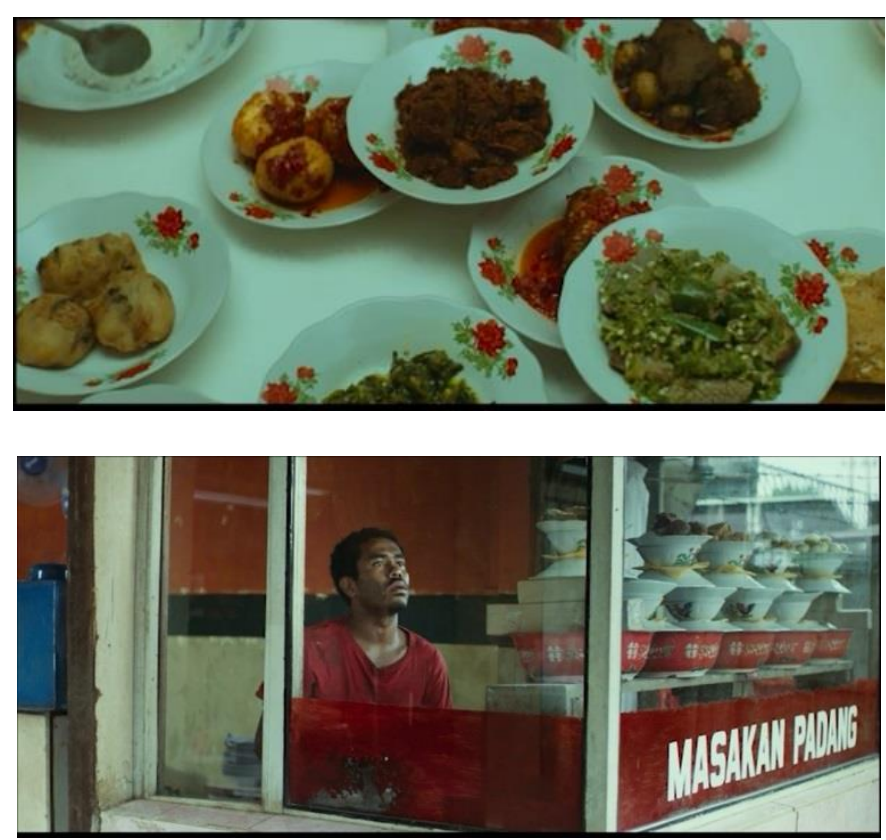

Gambar 4. Cara Penyusunan Piring ala Rumah Makan Padang Sumber: Film Tabula Rasa produksi Lifelike Pictures

\section{Kerja Keras dan Integritas di Balik Sebuah Makanan}

Film ini memang sarat akan pesan moral tanpa ada kesan menggurui, sesuai dengan ulasan Adham T. Fusama (2014). Pesan moral akan kebersamaan, kebhinekaan, tidak berprasangka, dan belas kasih terlihat jelas pada plot yang disampaikan. Namun, daya tarik moral yang secara khusus berkenanaan dengan pengalaman gastronomi terletak pada kerja keras dan integritas yang dipegang teguh untuk dapat menyajikan sepiring masakan Padang yang lezat ke meja pelanggan. 
Dalam film diperlihatkan bahwa para karakter yang terlibat dalam warung makan Takana Juo memulai hari-harinya dari pagi buta hingga malam. Sejak subuh Mak dan Hans sudah berangkat ke pasar, dimana di sana juga para pekerja pasar juga telah memulai kesibukan mereka. Kemudian, ditampilkan pula scene dimana Hans memanggul sekarung besar beras untuk dibawa pulang ke warung sambil berjalan kaki. Diceritakan pula bahwa memasak Rendang membutuhkan waktu empat jam diaduk dengan pelan dan sabar, serta keteguhan Mak untuk mempertahankan proses memasak tradisional dan penggunaan bahan berkualitas. Adegan-adegan tersebut semuanya menunjukkan betapa kerasnya mereka bekerja dan keteguhan integritas mereka dalam mengelola rumah makan Padang tersebut, di tengah beban hidup dan persaingan yang semakin ketat.

Perkataan Matthew Riordan (2015) dalam ulasannya, bahwa "Tabula Rasa is a moving and gratifying watch that might just change the way you look at your next meal." (Terjemahan: Tabula Rasa adalah sebuah tontonan yang mengharukan dan memuaskan yang mungkin akan mengubah cara anda memandang makanan anda selanjutnya), menunjukkan bahwa penonton mampu memahami pesan yang ingin disampaikan oleh cerita ini. Pesan tersebut hadir sebagai suatu konteks sosial keberadaan masakan Padang yang dapat mempengaruhi penonton secara emosional dan moral untuk mengonsumsi masakan Padang. Film ini mencoba menunjukkan suatu makna lebih dari sepiring makanan. Sepiring Rendang yang menjadi makanan terlezat versi CNN Reader's Choice Award (2017) tersebut juga membawa rantai panjang harapan dan integritas dari para pekerja di balik hadirnya kelezatan masakan tersebut. Selain itu, film ini juga mencoba melekatkan simbol kekeluargaan, kebersamaan, dan kerinduan akan rumah yang akan dibahas pada bagian berikutnya. 


\section{Pesona Kekeluargaan dan Kerinduan akan Kampung Halaman}

Tujuan umum suatu kegiatan promosi adalah untuk menginformasikan audien mengenai suatu produk, membujuk agar terjadi pembelian, dan juga mengingatkan pelanggan mengenai pengalaman-pengalaman yang berkenaan dengan kualitas suatu produk (Perreault dan McCarthy, 2002: 398). Tujuan umum tersebut, walaupun dapat dilihat secara terpisah dalam memilih tujuan utama dari suatu promosi, namun, antara tujuan satu dan lainnya juga dapat saling mempengaruhi. Untuk membujuk calon pembeli agar membeli suatu produk bisa juga ditempuh dengan cara memberikan informasi-informasi maupun dengan cara mengingatkan mengenai pengalaman pelanggan ketika menggunakan produk tersebut.

Dalam film Tabula Rasa, baik dari sudut plot cerita, visual yang ditampilkan, serta pemilihan soundtrack dan movie scoring, semuanya mengarah kepada pembangkitan memori tentang masa lalu dan kerinduan akan kampung halaman. Hal ini dapat bekerja dengan baik untuk mengingatkan penonton tentang pengalaman mengkonsumsi masakan Padang yang pernah dilakukannya, maupun juga pengalaman mengunjungi Indonesia. Seperti yang terjadi pada seorang informan bernama Renata Widjaja (36 Tahun, Programmer - USA), seorang imigran Indonesia di Amerika Serikat, yang merasa bahwa dia merasa rindu untuk mengkonsumsi masakan Padang di Indonesia setelah melihat visual film Tabula Rasa.

Gulai Kepala Kakap juga secara gamblang disebutkan sebagai suatu pengingat akan kampung halaman dan keluarga oleh tokoh Mak dan Parmanto dalam beberapa dialog. Simbolisasi akan kerinduan terhadap keluarga juga terlihat dari soundtrack yang digunakan dalam film ini. Pada sebuah adegan, diperlihatkan beberapa peralihan scene antara shot Hans yang sedang berada di tengah alam Serui - Papua, shot warung Takana Juo yang ramai pengunjung, shot suasana pasar 
dengan cuplikan close up beberapa pedagang pasar yang sedang bekerja, dan juga close up shot Parmanto yang sedang berpeluh saat memasak di dapur Caniago, kemudian diakhiri oleh shot foto keluarga Mak (Gambar 5). Pada adegan tersebut diletakkan suatu soundtrack dari band Dialog Dini Hari yang salah satu personelnya ditampilkan sebagai seorang pengamen dalam adegan tersebut. Lirik dari lagu tersebut adalah sebagai berikut (sumber: Film Tabula Rasa produksi Liflike Pictures):

Jauh sudah ku berkelana

Arungi luasnya hamparan laut dan darat gunung dan lembah

Merengkuh Jarak menggapai impian

Lelah sudah kubergiat

Menguras Peluh Membanting tulang

Lewati senang sedih canda dan tangis

Langkahi hari demi hari

Namun, di balik semua itu

Di lubuk hati ini

Slalu tersimpan rasa yang tak pernah hilang

Kadang berkelebat kadang berjejak

Lukisan indah kampung halamanku

Wajah-wajah keluarga, sahabat dan sanak saudara

Tempat berbagai kenangan indah 

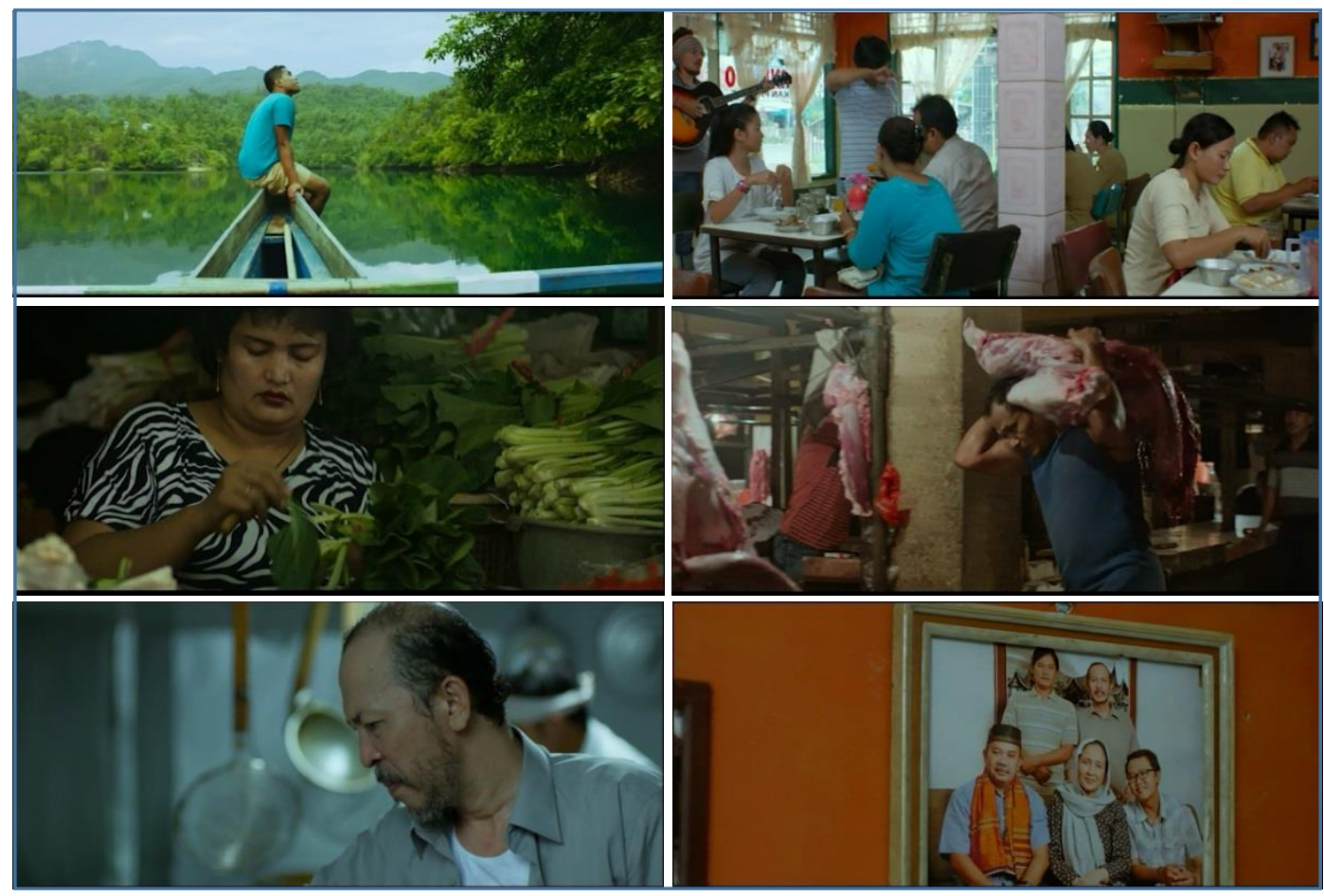

Gambar 5. Rangkaian Scene dengan Soundtrack Gurat Asa Sumber: Film Tabula Rasa produksi Lifelike Pictures

Dapat dilihat bahwa gabungan antara lirik lagu dan visual adegan yang ditampilkan menguatkan simbolisasi akan kerinduan terhadap kampung halaman dari para karakter dalam film. Dalam kasus film ini, kerinduan akan kampung halaman dan keluarga tersebut juga dilekatkan kepada masakan Padang sebagai tali merah antara karakter-karakter tersebut. Film ini tampaknya juga dapat meraih para perantau yang jauh dari keluarga atau kampung halaman karena berbagai alasan, termasuk juga para imigran Indonesia yang menetap di luar negeri.

Ulasan lain yang mengatakan bahwa Tabula Rasa penuh rasa nostalgia disampaikan oleh Rizky Puji (2014) dengan mengatakan bahwa, "Tabula Rasa is heartwarming and wistfully nostalgic, just like homemade meal."(Terjemahan: Tabula Rasa memberikan rasa hangat dan nostalgia yang sendu, tepat seperti makanan buatan rumah). Rasa nostalgia ini juga ditampilkan oleh film melalui pemilihan soundtrack lagu-lagu nostalgia Indonesia dengan nuansa suara vinyl (piringan 
hitam), seperti lagu 'Teluk Bayur' oleh Ernie Djohan dan 'Iseng Bersama' oleh Sam Saimun dan Elly Srikudus. Lagu bergenre Melayu berjudul 'Mak Inang Pulau Kampai' oleh Orkes Tropicana Medan dan movie scoring dengan beberapa nuansa etnis Papua, juga menambah nuansa kekayaan kelokalan Indonesia. Hal ini bertalian dengan konteks budaya yang berusaha dilekatkan pada masakan-masakan yang ditampilkan dalam film. Konteks budaya ini menjadikan masakan-masakan tersebut bukan hanya sekedar tampak lezat namun terdapat satu set kekayaan budaya dan cara hidup (way of life) Indonesia yang ikut bersamanya yang kemudian dapat membentuk citra masakan khas Indonesia yang penuh kearifan lokal.

\section{Kesimpulan}

Daya tarik yang disampaikan dalam film ini mengarah kepada penguatan reputasi masakan Padang sebagai salah satu daya tarik pariwisata gastronomi Indonesia. Reputasi merk tersebut tersaji dalam bentuk brand identity, brand integrity, dan brand image. Film ini dapat membantu menguatkan reputasi masakan Padang, khususnya Rendang, yang telah dinobatkan sebagai makanan terenak di dunia versi CNN Reader's Choice Award (2017). Brand identity muncul dalam bentuk keunikan proses memasak tradisional, cara penyajian khas rumah makan Padang, hingga cara makan khas Indonesia. Keunikan proses memasak masakan secara tradisional yang masih dipertahankan juga menjadi bagian dari brand integrity bersama dengan penggunaan bahan-bahan berkualitas. Kedua hal tersebut dapat berkontribusi dalam membentuk citra masakan Padang (brand image) dimana kelezatannya muncul karena rangkaian kearifan lokal yang tetap dipertahankan. Film ini juga dapat memperkuat citra masakan Padang yang dekat dengan kesan perantauan dan kerinduan akan keluarga. Seperti yang dikemukakan oleh Kotler, et.al (2010: 34-45) mengenai pengaruh kuatnya citra merk terhadap keputusan pembelian, citra masakan Padang yang dibangun dalam film ini dapat memperkuat alasan emosional calon konsumen untuk mengkonsumsi masakan Padang ketimbang alasan 
rasionalnya, sehingga kecilnya alasan rasional yang ditampilkan tidak lagi menjadi kekurangan yang patut dipermasalahkan.

Film "Tabula Rasa" ini banyak menampilkan scene-scene yang berkenaan dengan makanan dan proses membuat makanan. Walaupun secara prestasi, film Tabula Rasa berhasil ditampilkan di festival-festival film internasional, ternyata tidak banyak khalayak yang mengetahui tentang film ini. Namun, kurang populernya film ini di Indonesia, tidak serta merta menjadikan film ini tidak berpotensi sebagai alat promosi untuk makanan Indonesia pada khususnya, serta pariwisata Indonesia pada umumnya. Lebih lagi, pemilihan masakan Padang sebagai penggerak cerita juga cukup menguntungkan, karena rumah makan masakan Padang terkenal akan penyebarannya yang luas hingga ke mancanegara. Hal ini tentu saja akan menjadikan proses promosi pariwisata yang diinduksi oleh film Tabula Rasa akan menjadi berkesinambungan, dengan dimudahkannya penonton, terutama yang berada di luar negeri, untuk mencoba kelezatan sajian masakan Padang.

\section{Daftar Pustaka}

Antara News. 2015. "Film-film Indonesia di Cannes", sumber URL: https://www.antaranews.com/berita/496437/film-film-indonesia-di-cannes diakses 15 Mei 2018

Antara News. 2018. “Tabula Rasa Film Indonesia di SIFF Bulgaria”, sumber URL: https://www.antaranews.com/berita/696063/tabula-rasa-film-indonesiapertama-di-siff-bulgaria diakses 20 Agustus 2018

Beeton, Sue. 2005. Aspect of Tourism: Film Induced Tourism. Chris Cooper, et.al [Eds.]. Clevedon: Channel View Publication.

Chandler, D. 2007. Semiotics: The Basics. New York: Routledge.

CNN. 2015. "Promosi Wisata Gratis Lewat Film Indonesia", sumber URL: https:/www.cnnindonesia.com/hiburan/20150528134246-220-56279/promosiwisata-gratis-lewat-film-indonesia diakses 15 Mei 2018

CNN. 2017. "Your Pick: World's 50 Best Foods", sumber URL: https://edition.cnn.com/travel/article/world-best-foods-readerschoice/index.html diakses 15 Mei 2018 
Expedia. 2016. "Expedia Millenial Traveller Report", sumber: URL: https://www.foresightfactory.co/wp-content/uploads/2016/11/ExpediaMillennial-Traveller-Report-Final.pdf diakses 23 Juli 2018

Fusama, Adham T. 2014. “[Resensi Film] Tabula Rasa (2014) - Adriyanto Dewo", sumber: URL: https://adhamology.wordpress.com/2014/09/24/resensi-filmtabula-rasa-2014-adriyanto-dewo/ diakses 15 Juli 2018

Giaji, Kukuh. 2014. "Review Tabula Rasa", sumber: URL: https://kgiaji.wordpress.com/2014/10/11/review-tabula-rasa-2014/

diakses 15 Juli 2018.

Hall, S. 1999. “Encoding, Decoding”. Cultural Studies Reader. Second Edition. Simon During (Ed.). 507-517p. London: Routledge.

Huang, Guanxiong. 2013. Mediating Tourist Landscape: A Case Study of MediaInduced Tourism in China. International Journal of Communication, Vol 7, p 2678 - 2696. [cited 12 Juli 2018]. Available from URL: http://ijoc.org/index.php/ijoc/article/viewFile/1905/1038

Hudson, S. J.R.B. Ritchie. 2006. Promoting Destination via Film Tourism: An Empirical Identification of Supporting Markeying Initiative. Journal of Travel Research. p.387-396.

Imanjaya, Ekky dan Indra Kusumawardhana. 2016. Film Tourism Indonesian Style: The Cases of Laskar Pelangi and Eat Pray Love. Journal of Communication Studies, Vol. 3 No. 2. [cited 12 Juli 2018]. available from URL : https://www.academia.edu/36416886/Film_Tourism_Indonesian_Style_The_C ases_of_Laskar_Pelangi_and_Eat_Pray_Love

IMDB. $2014 . \quad$ "Film Tabula Rasa. sumber URL: https://www.imdb.com/title/tt3694000/ diakses 15 Mei 2018

Kementerian Luar Negeri R.I. 2018a. "Film Tabula Rasa Tayang di Sofia International Film Festival", sumber URL: https://www.kemlu.go.id/id/berita/berita-perwakilan/Pages/Film-TabulaRasa-di-Sofia-International-Film-Festival.aspx diakses 15 Mei 2018

Kementerian Pariwisata R.I. 2018. “Once Again! Indonesia's RENDANG and NASI GORENG Crowned World's Best Foods", sumber URL: http://www.indonesia.travel/my/en/news/once-again-indonesia-s-rendangand-nasi-goreng-crowned-world-s-best-foods diakses 15 Mei 2018

Kotler, Philip, et.al. 2010. Marketing 3.0: From Products to Customer to the Human Spirit. New Jersey: John Wiley \& Sons Inc.

Kotler, Philip, Gary Armstrong. 2012. Principles of Marketing. (14th ed). New Jersey: Prentice Hall. 
Liputan 6. 2014. “Tabula Rasa Film Kuliner Pertama Tanah Air", sumber URL: https://www.liputan6.com/showbiz/read/2107068/tabula-rasa-film-kulinerpertama-tanah-air diakses 15 Mei 2018

Lukitasari, Rimalinda. 2017. Bujukan Berwisata ke Bali: Simbol-simbol Promosi Pariwisata Film 'Eat Pray Love'. Jurnal Master Pariwisata, Vol.3 No 2: 323338.

Metro TV News. 2014. "Tabula Rasa Film Kuliner Pertama di Indonesia”, sumber URL: $\quad$ http://hiburan.metrotvnews.com/read/2014/08/18/279098/tabula-rasafilm-kuliner-pertama-di-indonesia diakses 15 Mei 2018

Morissan. 2010. Periklanan: Komunikasi Pemasaran Terpadu. Jakarta: Kencana.

Perreault, William D., et.al. 2011. Basic Marketing: A Marketing Strategy Planning Approach. New York: McGraw-Hill

Piliang, Y. A. 2012. Semiotika dan Hipersemiotika: Kode, Gaya dan Matinya Makna. Bandung: Matahari.

Puji, Rizky. 2014. “Tabula Rasa (2014)", sumber: URL: https://karamelkinema.wordpress.com/2014/09/25/tabula-rasa-2014/ diakses 15 Juli 2018

Purwasito, Andrik. 2006. Semiologi Komunikasi. Mediator. Vol. 7. No. 1. [cited 9 December 2015] Available from: URL: http://ejournal.unisba.ac.id/index.php/mediator/article/view/1268/771

Ramadhan, Rizky. 2014. "8 Rasa yang Membekas dari Film Tabula Rasa”, sumber: URL: http://www.provoke-online.com/index.php/film/moviereview/2959-8rasa-yang-membekas-dari-film-tabula-rasa diakses 15 Juli 2018.

Republika. 2014. "Tabula Rasa Film Kuliner Pertama Indonesia”, sumber URL: https://www.republika.co.id/berita/senggang/film/14/09/18/nc36st-tabularasa-film-kuliner-pertama-indonesia diakses 15 Mei 2018

Richards, Greg. 2002. Gastronomy: An Essential Ingredient in Tourism Production and Consumption. Tourism and Gastronomy. Hjalager, A.M., Richards, G., ed. p.3-20. London: Routledge.

Riordan, Matthew. 2015. "Film Review: Tabula Rasa (2014)", sumber: URL: https://www.filmdoo.com/blog/2015/12/15/film-review-tabula-rasa-2014/ diakses 15 Juli 2018

Sobur, Alex. 2013. Semiotika Komunikasi. Bandung: PT. Remaja Rosdakarya

Stevano Timothy. 2014. “Tabula Rasa (2014) Review”, sumber: URL: http://kritikusfilmgadungan.blogspot.com/2014/10/tabula-rasa-2014review.html diakses 15 Juli 2018 
Tabula Rasa. 2014. Sumber URL: http://www.tabularasafilm.com diakses 15 Mei 2018

Thwaites, T., et.al. 2011. Introducing Cultural and Media Studies: Sebuah Pendekatan Semiotik. Yogyakarta: Jalasutra.

Yoeti, Oka A. 2013. Pemasaran Pariwisata. Bandung: Angkasa

\section{Profil Penulis}

Rimalinda Lukitasari menyelesaikan program diploma satu Bahasa Inggris di UPT Lab Bahasa Universitas Udayana (2006) dan gelar strata satu Sastra Inggris dari Fakultas Sastra Universitas Udayana (2010). Pada tahun 2016, penulis menyelesaikan studinya di Program Studi Kajian Pariwisata Program Pascasarjana Universitas Udayana dan memperoleh gelar Magister Pariwisata. Saat ini penulis aktif di bidang pendidikan sebagai seorang dosen pada Program Studi D4 Manajemen Perhotelan di Politeknik Internasional Bali. Di dunia profesional, penulis adalah seorang penulis untuk konten media-media promosi bagi pelaku industri pariwisata (copywriter), dan juga berkecimpung dalam dunia manajemen konvensi dan perhelatan. 